\title{
Dynamic Mechanical Behavior of Rock Materials
}

\author{
Farzad Naseri ${ }^{*}$, Sina lotfollahi² ${ }^{2}$ Ahad Bagherzadeh khalkhali \\ ${ }^{1}$ Department of Civil Engineering, Islamic Azad University-Electronic Branch, Tehran, Iran \\ ${ }^{2}$ Department of Civil Engineering, University of Mohaghegh Ardabili, Ardabil, Iran \\ ${ }^{3}$ Irrigation and Drainage Engineering, Aburaihan Campus, University of Tehran, Pakdasht, Tehran, Iran
}

${ }^{*}$ Correspondence should be addressed to Farzad Naseri, Department of Civil Engineering, Islamic Azad University-Electronic Branch, Tehran, Iran; Tell: +989120256605; Fax: +989120256605; Email: Naseri.farzad@iauec.ac.ir.

\begin{abstract}
Dynamic rock mechanics investigates the mechanical behavior of rock under dynamic loading conditions and change in mechanical properties of the rock. Loading techniques were almost used for both intermediate and high strain rate tests. In this work, dynamic tests and dynamic mechanical behavior of rock materials were studied. Dynamic tests were discussed to predict the stress-strain behavior. Different dynamic mechanical properties of rock materials including uniaxial and triaxial compressive strength, tensile strength, shear strength and fracture toughness were summarized. The effect of pressure, temperature and water saturation as well as microstructure, size and shape of rock on the mechanical properties of rock materials was considered.
\end{abstract}

Key words: Dynamic, Rock, Mechanical behavior, Strain.

Copyright (C) 2017 Farzad Naseri et al. This is an open access paper distributed under the Creative Commons Attribution License.

Journal of Civil Engineering and Materials Application is published by Lexis Publisher; Journal p-ISSN xxxx-xxxx; Journal e-ISSN 2588-2880.

\section{INTRODUCTION}

$\mathrm{T}$ The influence of dynamic loading on rock is a key factor for various rock engineering problems (1). Different applications of rock dynamics is in earthquakes, mining, energy, environmental and civil engineering. Various environmental parameters such as confining pressure, temperature and ground water as well as rock factors such as microstructure, size and shape of the rock have significant effect on the dynamic mechanical behavior of rock materials (2-5). In recent years, the experimental techniques were developed to characterize the dynamic mechanical behavior of materials (6-8). In previous studies, dynamic experimental techniques were studied for rock-like materials such as concrete, mortar, ceramic and rock materials (9-12). In this work, dynamic experimental techniques and mechanical behavior of rock material have been reviewed. The experimental techniques for intermediate and high strain rate tests and dynamic mechanical behaviors of rock materials were discussed.

\section{LOADING METHODS FOR INVESTIGATION OF DYNAMIC BEHAVIOR}

Loading techniques have been used for investigation of dynamic behavior of rock materials. The loading techniques for rock materials are illustrated in Figure 1. In the range of $10^{-8}-10^{-5} \mathrm{~s}^{-1}$ strain rate, the creep behavior is considered and creep laws are used (5). In the range of $10^{-}$ ${ }^{5}-10^{-3} \mathrm{~s}^{-1}$ strain rate, the quasi-static stress-strain curve obtained from constant strain rate (CSR) test has been applied to investigate the mechanical behavior (13). The ordinary hydraulic servo-controlled testing machines and hydraulic oil machines, can load specimens at strain rates up to $10^{-3}$ and $10^{-1} \mathrm{~s}^{-1}$, respectively. The pneumatichydraulic machines and drop-weight machines have been developed to reach strain rates on the order of $10^{0}$ and $10^{1}$ $\mathrm{s}^{-1}$, respectively (1). The mechanical behavior of rock materials at strain rates ranging from $10^{-1}$ to $10^{1} \mathrm{~s}^{-1}$ is defined as intermediate strain rate. The loading techniques in the high strain rate, in the range of $10^{1}$ to $10^{4} \mathrm{~s}^{-1}$ are the split Hopkinson pressure bar (SHPB). At high strain rates, there is a transition from nominally isothermal condition to quasi-isothermal/adiabatic condition (14). 


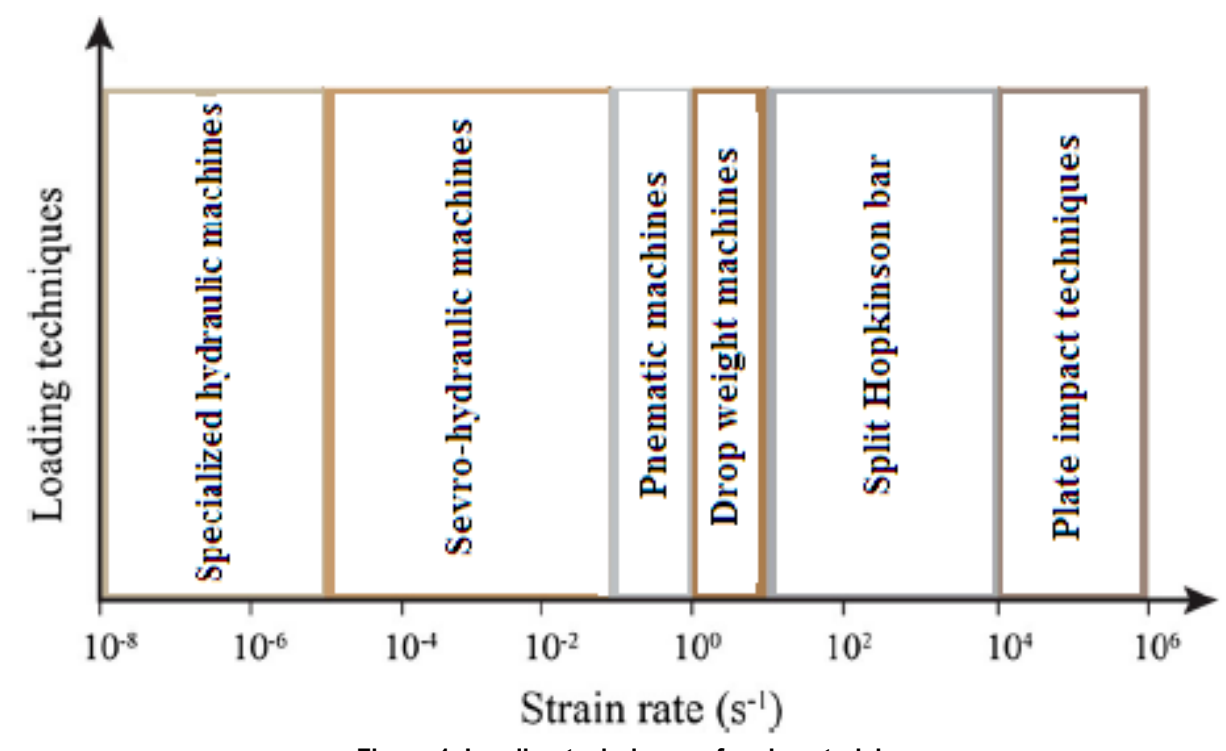

Figure 1. Loading techniques of rock materials

Pneumatic-hydraulic machines have developed for studying the intermediate strain rate behavior of rock materials in uniaxial compression. In pneumatic-hydraulic machines, the load is used by movement of a light weight piston driven by expansion of compressed gas. The strain rate is dependent on the relationship between the specimen stiffness and machine stiffness (15). The principle of dropweight machines is gravitational potential energy, through controlling a hammer with known height and weight. Drop-weight machines have been used to achieve strain rate of $10^{1} \mathrm{~s}^{-1}$. The use of drop-weight machines is limited due to their problems including 1) the technique is passive, and testing conditions are determined by trial and error or from empirical parameters, 2) the rate and form of the compressive loading depend on both the specimen and machine compliances, as well as the average energy of the falling weight, 3 ) great care should be taken in interpreting experimental data because of the coupling effects between machine vibration and wave propagation, 4) the calculated displacement might be inaccurate, 5) the loading rate cannot be well controlled, and thus multi-axial tests are unreliable (16). The loading techniques at high strain rate have been widely utilized with the split Hopkinson bar. The structure split Hopkinson bar is a striker bar, an incident bar and a transmission bar, with a specimen sandwiched between the incident and transmission bars.

The strain rate $(\grave{\varepsilon})$ is given as follows (17):

$\varepsilon^{\bullet}=\frac{\left(u_{1}^{\bullet}-u_{2}^{\bullet}\right)}{L_{s}}$

where $\mathrm{u}_{1}$ and $\mathrm{u}_{2}$ are the velocities at the incident barspecimen and specimen-transmitted bar interfaces, respectively. $L_{s}$ is the length of strike bar. The conditions of constant stress rate and stress equilibrium need to be satisfied simultaneously for a split Hopkinson bar test. To reach the stress equilibrium condition, it has been suggested that the equilibrium time should be 5-10 times of transit time (18). The end friction between the specimen and the loading device may lead to a complex stress state of multi-axial compression, and rock materials are very sensitive to the confining pressure. Although fiction effects can be physically minimized in tests by proper lubrication, they cannot be eliminated completely. The friction could be decreased using numerical simulations by different contact conditions including lubricated, dry and bonded using high-strength adhesive (19). Furthermore, the stress wave loading in high strain rate tests causes inertia to have an influence on measured mechanical properties (20). The magnitude of the inertial contribution to the apparent stress depends also on the density and size of the speciem. Powell (21) has been investigated the radial inertia effects on rock behavior. They observed that the radial stress increased towards the center of the specimen during fracturing, and concluded that failure propagates inwardly in a progressive manner. Three modifications were used to push the Split Hopkinson bar to higher strain rates. These modifications were, 1) decrease of the specimen size, especially the length; 2) direct impact on the specimen; and 3) miniaturization of the entire system (21). The first approach is typically limited by frictional effects (22). A projectile directly impacts on a specimen placed in front of an elastic bar in the second approach. Several miniaturized versions on the millimeter order in diameter have been developed, and the strain rate can reach up to about $10^{5} \mathrm{~s}^{-1}$ in the third approach (22).

\section{DYNAMIC MECHANICAL PROPERTIES OF ROCK MATERIALS}

The mechanical properties of rock materials are sensitive to loading rate, and enhancement in mechanical properties of rock materials. On the other hand, the dynamic mechanical properties and fracture behaviors of rock materials depend on the loading and measurement technique, testing method and influencing environmental 
factors (23).

\subsection{Uniaxial Compression Tests}

The uniaxial compression tests were conducted under dynamic loading in different measurement type and different size, shape (e.g. cube, cylinder or prism) and aspect ratio of the specimens. The size and shape of the specimen are normally defined by the same value of the ratio $\mathrm{L}_{\mathrm{s}} / \mathrm{D}_{\mathrm{s}}$ of 2.5-3.0 for quasi-static tests. Furthermore, the diameter should be close to $50 \mathrm{~mm}$ or at least 10 times the average grain size, with the ratio $L_{s} / D_{s}$ taking values of $1: 1$ and $0.5: 1$ for small and large specimens, respectively (24).

\subsection{Triaxial Compression Tests}

In triaxial compression tests, the specimen is placed inside a pressure chamber and isotropically loaded by hydrostatic pressure using various confining fluids (Figure 2) (16). The confining pressure depends on the thickness and material type of the sleeve. Strain gauges are mounted on the sleeve surface to record the stress state of the specimen. General trends exist for: an increase of triaxial strength with increasing strain rate at all confining pressures; an increase of triaxial strength with increasing confining pressure, as had been demonstrated in quasi-static tests; the deformation behavior to become more ductile at HSR; and a lower confining pressure than in quasi-static tests, in particular for sedimentary materials $(16,25)$.

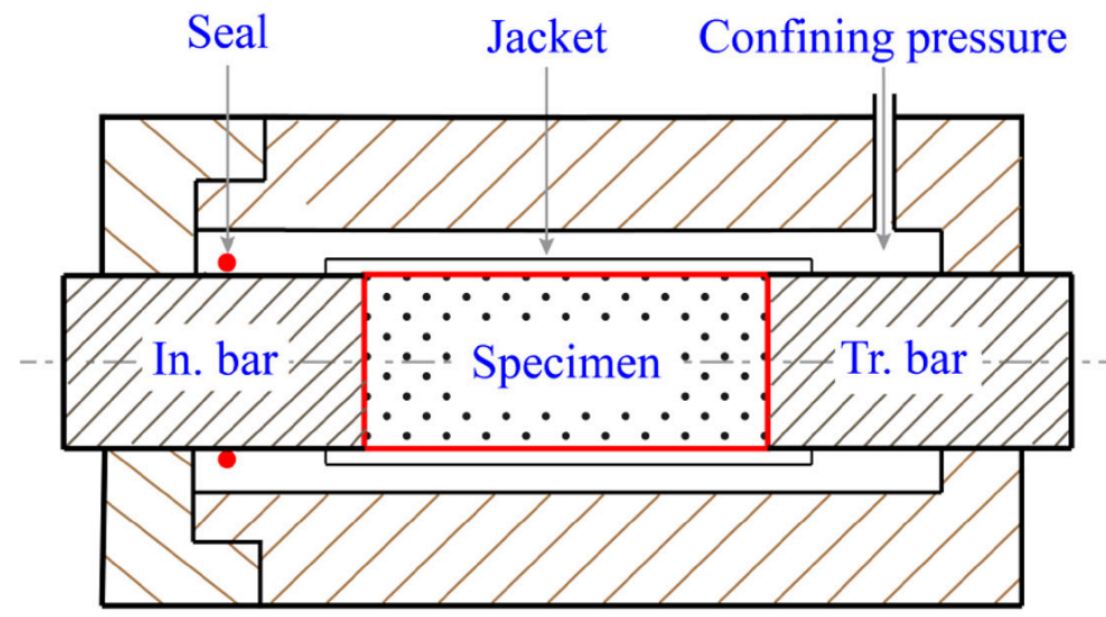

Figure 2. Schematic of triaxial compression tests design

\subsection{Tension tests}

There are two types of standard methods including direct tension and indirect tension. Direct tension tests under quasi-static loads are difficult to perform because even very slight misalignments and stress concentrations in the loading system may produce undesirable failure modes. The schematics of four types of split Hopkinson tension bar techniques are illustrated in Figure 3 (26). The limitations on direct tension tests include the following: (1) the same limitations as for quasi-static tests; (2) the complexity of the specimen shape and (3) pulse shaping techniques are hard to apply, thus the condition of stress equilibrium may be violated (27). To overcome these problems, indirect tension methods have been developed. Indirect testing methods provide a convenient alternative in terms of specimen manufacturing, experimental setup and data reduction, to determine the tensile strength (28). The schematic of indirect tension methods is illustrated in Figure 4. (a)

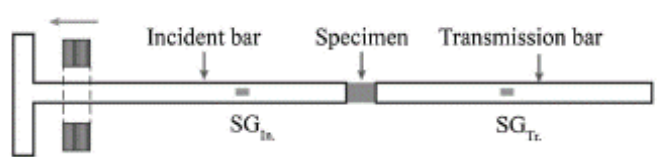

(c)

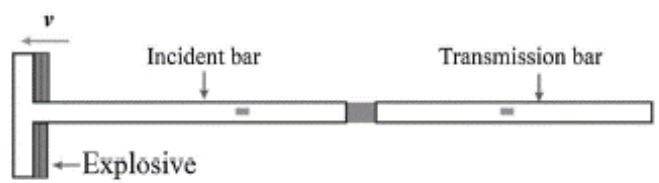

(b)

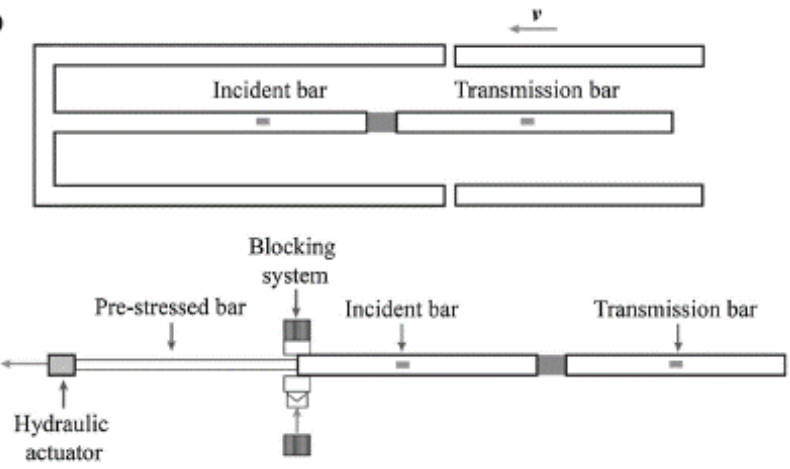

Figure 3. Schematics of four types of split Hopkinson tension bar techniques: (a) a mass is impacted directly on an anvil attached to the incident bar; (b) an anvil is loaded by a compressive wave transmitted through a hollow tube; (c) a pulse is generated by the detonation of an explosive against the anvil; and (d) a pre-stressed bar is connected to the incident bar to produce the loading pulse 


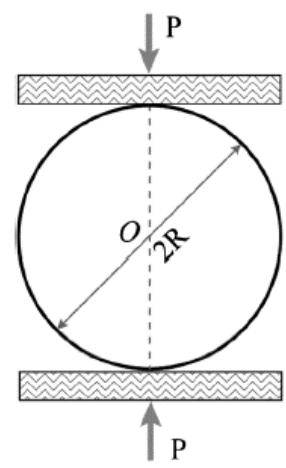

(a)

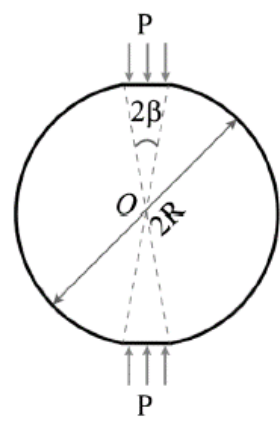

(b)

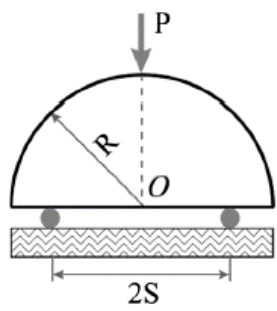

(c)

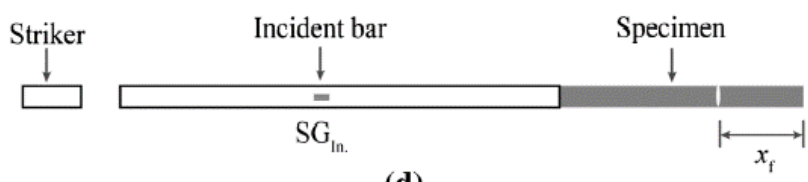

(d)

Figure 4. Schematics of indirect tension testing methods: (a) Brazilian disc, (b) flattened Brazilian disc, (c) semi-circular bending and (d) spalling

\subsection{Shear tests}

For higher strain rates, the torsional split Hopkinson bar technique has been developed, which overcomes the limitations of lateral inertia, friction and wave dispersion effects on the experimental results in the traditional Split Hopkinson pressure bar test (29). The dynamic shear strength of the thin-walled tubular specimen, $\tau_{\mathrm{d}}$, is calculated from the dynamic torque, $T_{d}$, as follows (29):

$\tau_{d}=\frac{T_{d}}{2 \pi R^{2} B_{w s}}$ where $\mathrm{B}_{\mathrm{ws}}$ is the wall thickness and $\mathrm{R}$ is the mean radius of the specimen.

\subsection{Stress-strain behavior at high strain rate}

The strength, strain to failure, Young's modulus, Poisson's ratio and brittle/ductile behavior can be evaluated from stress-strain curves. The stress-strain curves are almost evaluated by load transducers and on-specimen strain gauges without considering inertia effects. Methods for determining the stress-strain curve at high strain rate are illustrated in Table 1. Among them, the direct estimation method is recommended to determine the stress-strain curve (7).

Table 1. Methods for determining the stress-strain curve at high strain rate (7)

\begin{tabular}{lll}
\hline Method & Strain history $\varepsilon(t)$ & Stress history $\sigma(t)$ \\
\hline One-wave analysis & $\varepsilon(t)=-\left(2 C_{\mathrm{B}} / L_{\mathrm{s}}\right) \cdot \int_{0}^{t} \varepsilon_{\mathrm{Re} .}(t) d t$ & $\sigma(t)=\left(A_{\mathrm{B}} E_{\mathrm{B}} / A_{\mathrm{s}}\right) \cdot \varepsilon_{\mathrm{Tr} .}(t)$ \\
Two-wave analysis & $\varepsilon(t)=-\left(2 C_{\mathrm{B}} / L_{\mathrm{s}}\right) \cdot \int_{0}^{t} \varepsilon_{\mathrm{Re} .}(t) d t$ & $\sigma(t)=\left(A_{\mathrm{B}} E_{\mathrm{B}} / A_{\mathrm{s}}\right) \cdot\left[\varepsilon_{\mathrm{In} .}(t)+\varepsilon_{\mathrm{Re} .}(t)\right]$ \\
Three-wave analysis & $\varepsilon(t)=\left(C_{\mathrm{B}} / L_{\mathrm{s}}\right) \cdot \int_{0}^{t}\left[\varepsilon_{\mathrm{In} .}(t)-\varepsilon_{\mathrm{Re} .}(t)-\varepsilon_{\mathrm{Tr} .}(t)\right] d t$ & $\sigma(t)=\left(A_{\mathrm{B}} E_{\mathrm{B}} / 2 A_{\mathrm{s}}\right) \cdot\left[\varepsilon_{\mathrm{In} .}(t)+\varepsilon_{\mathrm{Re} .}(t)+\varepsilon_{\mathrm{Tr} .}(t)\right]$ \\
Direct estimate & $\varepsilon(t)=\left(C_{\mathrm{B}} / L_{\mathrm{s}}\right) \cdot \int_{0}^{t}\left[\varepsilon_{\mathrm{In} .}(t)-\varepsilon_{\mathrm{Re} .}(t)-\varepsilon_{\mathrm{Tr} .}(t)\right] d t$ & $\sigma(t)=\left(A_{\mathrm{B}} E_{\mathrm{B}} / A_{\mathrm{s}}\right) \cdot \varepsilon_{\mathrm{Tr} .}(t)$ \\
Foot-shifting & $\varepsilon(t)=\left(C_{\mathrm{B}} / L_{\mathrm{s}}\right) \cdot \int_{0}^{t}\left[\varepsilon_{\mathrm{In} .}(t)-\varepsilon_{\mathrm{Re} .}(t)-\varepsilon_{\mathrm{Tr} .}\left(t+t_{0}\right)\right] d t$ & $\sigma(t)=\left(A_{\mathrm{B}} E_{\mathrm{B}} / A_{\mathrm{s}}\right) \cdot \varepsilon_{\mathrm{Tr} .}(t)$ \\
Hybrid analysis & Direct measurement & One of the above or load transducer \\
& & \\
Inverse analysis & Combination of FEM simulation & Combination of FEM simulation \\
& and/or direct measurement & andor one of the above
\end{tabular}

\subsection{Dynamic uniaxial compressive behavior}

Dynamic mechanical parameters are usually obtained from stress-strain curves extracted directly from load transducers. In high strain rate testing, the effects of inertia and wave propagation should be considered (30). The increase or decrease with increasing the strain rate means that the critical strain becomes more brittle or ductile at higher strain rate. Young's modulus decreases slightly and the Poisson's ratio increases slightly with increasing loading rate. The inverse method employed force and 
particle velocities measured at both sides of the specimen, was successfully used to determine the stress-strain curves of concrete and salt. Therefore, the inverse analysis method produces accurate and repeatable results for rocklike materials at high strain rate. There is a definite increase in the uniaxial compressive strength of rock materials under dynamic loading (31).

\subsection{Dynamic triaxial compressive behavior}

Mechanical loads applied to rock materials are almost not uniaxial (32). The stress-strain curves at high strain rates under 0.1 and $10 \mathrm{MPa}$ confining pressures are approximately consistent with those under 27 and $55 \mathrm{MPa}$ confining pressures in the quasi-static tests, respectively. The used techniques were modified and improved to determine the triaxial compressive strength of rock-like materials precisely. The dynamic strength curve relative to confining pressure is almost parallel to the static one for rock materials. At constant confining pressure, the normalized dynamic triaxial compressive strength increases with increasing strain rate. The dynamic strength curve relative to confining pressure is almost parallel to the static one for rock materials, and the triaxial compressive strength at high strain rate is about $20-100 \%$ higher than those obtained in quasi-static tests $(33,34)$.

\subsection{Dynamic tensile behavior}

The tensile strength increases with increasing strain rate, whereas the strain decreases. The increase in the tensile strength and the decrease in the strain to failure, indicate that the material displays more brittle features in higher strain rate tests. The strain rates of the direct tension results are higher than those obtained by indirect tension testing methods, since the specimen sizes are usually smaller in indirect tension tests. Therefore, attempts have been made to determine the tensile stress-strain curve by means of indirect testing methods under quasi-static loads (35).

\section{CONCLUSION}

In this work, the dynamic mechanical behavior of rock materials is discussed. Loading techniques used for intermediate strain rate testing of rock materials are pneumatic-hydraulic, completely gas driven and dropweight machines. At high strain rate, the split Hopkinson bar is widely used, and major developments of this technique for rock materials. The strain rate in tests performed by loading techniques should be well controlled. Mechanical loads on engineering structures are commonly not uniaxial. Loading techniques can be applied for multiaxial stress, such as true-triaxial and compressionshear tests. Dynamic uniaxial and triaxial compressive, tensile and shear strength of rock materials are obtained by quantitative assessment of testing methods.

\section{FUNDING/SUPPORT}

Not mentioned any Funding/Support by authors.

\section{ACKNOWLEDGMENT}

Not mentioned any acknowledgment by authors.

\section{AUTHORS CONTRIBUTION}

This work was carried out in collaboration among all authors.

\section{CONFLICT OF INTEREST}

The author (s) declared no potential conflicts of interests with respect to the authorship and/or publication of this paper.

\section{REFERENCES}

1. Field JE, Walley S, Proud W, Goldrein H, Siviour C. Review of experimental techniques for high rate deformation and shock studies. International journal of impact engineering. 2004;30(7):725-75.

2. Nemat-Nasser $S$. High strain rate tension and compression tests. ASM hand book. 2000;8:427-8.

3. Walley S. Historical review of high strain rate and shock properties of ceramics relevant to their application in armour. Advances in Applied Ceramics. 2010;109(8):446-66.

4. Zhou Y, Zhao J. Advances in rock dynamics and applications: CRC Press; 2011.

5. Sharpe WN. Springer handbook of experimental solid mechanics: Springer Science \& Business Media; 2008

6 . Toutlemonde F, Gary G. Dynamic behavior of concrete: experimental aspects. Dynamic behavior of concrete and seismic engineering. 2009:1-54.

7. Zhang Q, Zhao J. A review of dynamic experimental techniques and mechanical behaviour of rock materials. Rock Mechanics and Rock Engineering. 2014;47(4):1411-78.

8. Zhao J, Zhou Y, Xia K. Advances in rock dynamics modelling, testing and engineering. Harmonising Rock Engineering and the Environment. 2011:147.

9. Zhao J, Zhou Y, Hefny A, Cai J, Chen S, Li H, et al. Rock dynamics research related to cavern development for ammunition storage. Tunnelling and Underground Space Technology. 1999;14(4):513-26.

10. Xia K, editor Status of characterization of strength and fracture properties of rocks under dynamic loading. Rock fragmentation by blasting: proceedings of the 10th international symposium on rock fragmentation by blasting; 2012: CRC Press.

11. Subhash G, Maiti S, Geubelle PH, Ghosh D. Recent advances in dynamic indentation fracture, impact damage and fragmentation of ceramics. Journal of the American Ceramic Society. 2008;91(9):2777-91.

12. Malvar LJ, Ross CA. Review of strain rate effects for concrete in tension. Materials Journal. 1998;95(6):735-9.

13. Gama BA, Lopatnikov SL, Gillespie JW. Hopkinson bar experimental technique: a critical review. Applied mechanics reviews. 2004;57(4):223-50.

14. Kuhn H, Medlin D. ASM Handbook. Volume 8: Mechanical Testing and Evaluation. ASM International, Member/Customer Service Center, Materials Park, OH 44073-0002, USA, 2000 998. 2000.

15. Cadoni E. Dynamic characterization of orthogneiss rock subjected to intermediate and high strain rates in tension. Rock Mechanics and Rock Engineering. 2010;43(6):667-76.

16. Chen WW, Song B. Split Hopkinson (Kolsky) bar: design, testing and applications: Springer Science \& Business Media; 2010.

17. Gray III GT. Classic split-Hopkinson pressure bar testing. ASM Handbook, Mechanical testing and evaluation. 2000;8:462-76.

18. Foster J. Comments on the validity of test conditions for Kolsky bar testing of elastic-brittle materials. Experimental mechanics. 2012;52(9):155963.

19. Hartley R, Cloete T, Nurick G. An experimental assessment of friction effects in the split Hopkinson pressure bar using the ring compression test. International Journal of Impact Engineering. 2007;34(10):1705-28.

20. Davies E, Hunter S. The dynamic compression testing of solids by the method of the split Hopkinson pressure bar. Journal of the Mechanics and Physics of Solids. 1963;11(3):155-79.

21. Young C, Powell C, editors. Lateral inertia effects on rock failure in splitHopkinson-bar experiments. 20th US Symposium on Rock Mechanics (USRMS); 1979: American Rock Mechanics Association.

22. Hakalehto KO. A study of the dynamic behaviour of rock using the Hopkinson split bar method: University of Minnesota; 1967.

23. Perkins R, Green S, Friedman M, editors. Uniaxial stress behavior of porphyritic tonalite at strain rates to 103 /second. International Journal of Rock Mechanics and Mining Sciences \& Geomechanics Abstracts; 1970: Elsevier. 24. Siviour C, Grantham S. High resolution optical measurements of specimen deformation in the split Hopkinson pressure bar. The Imaging Science Journal. 2009;57(6):333-43.

25. Gary G, Bailly P. Behaviour of quasi-brittle material at high strain rate. Experiment and modelling. European Journal of Mechanics-A/Solids. 1998;17(3):403-20.

26. Asprone D, Cadoni E, Prota A, Manfredi G. Dynamic behavior of a Mediterranean natural stone under tensile loading. International Journal of Rock Mechanics and Mining Sciences. 2009;46(3):514-20.

27. Huang S, Xia K, Dai F. Establishment of a dynamic Mohr-Coulomb failure criterion for rocks. International Journal of Nonlinear Sciences and Numerical Simulation. 2012;13(1):55-60.

28. Lu Y, Li Q. About the dynamic uniaxial tensile strength of concrete-like materials. International journal of impact engineering. 2011;38(4):171-80. 
29. Gilat A, Cheng C-S. Torsional split Hopkinson bar tests at strain rates above 104s-1. Experimental Mechanics. 2000;40(1):54-9.

30. Omidvar M, Iskander M, Bless S. Stress-strain behavior of sand at high strain rates. International journal of impact engineering. 2012;49:192-213.

31. Dai $F$, Xia K, Zheng H, Wang Y. Determination of dynamic rock modefracture parameters using cracked chevron notched semi-circular bend specimen. Engineering fracture mechanics. 2011;78(15):2633-44.

32. Kawakita M, Kinoshita S. The dynamic fracture properties of rocks under

confining pressure. Memoirs of the Faculty of Engineering, Hokkaido University. 1981;15(4):467-78.
33. Christensen R, Swanson S, Brown W. Split-Hopkinson-bar tests on rock under confining pressure. Experimental Mechanics. 1972;12(11):508-13.

34. Frew DJ, Akers SA, Chen W, Green ML. Development of a dynamic triaxial Kolsky bar. Measurement Science and Technology. 2010;21(10):105704.

35. Carmona S, Aguado A. New model for the indirect determination of the tensile stress-strain curve of concrete by means of the Brazilian test. Materials and structures. 2012;45(10):1473-85. 